\title{
Treatment of partial thickness burns of the face with Acticoat7 ${ }^{\mathrm{TM}}$
}

\section{A retrospective single center study}

\author{
Jakob Nedomansky · Alan Oramary · Stefanie Nickl · Gunther Fuchs · Christine Radtke · Werner Haslik • \\ Alexandra Fochtmann-Frana
}

Received: 4 August 2020 / Accepted: 6 October 2020 / Published online: 30 October 2020

(C) The Author(s) 2020

\begin{abstract}
Summary
Background The face is affected in more than $50 \%$ of patients with extensive burn trauma. Effective treatment is of importance to avoid hypertrophic scarring, functional impairment and social stigmatization. Material and methods All patients treated with Acticoat $7^{\mathrm{TM}}$ due to superficial and deep partial thickness burns of the face between 2008 and 2017 at the intensive care unit (ICU) for burn trauma at the Department for Plastic and Reconstructive Surgery of the Medical University of Vienna were retrospectively analyzed. Patients were evaluated for the number of required dressing changes until complete re-epithelialization, bacterial colonization, potential complications and the need for primary and secondary surgery. Results A total of 100 patients were analyzed. It took a median dressing change rate of 1 (range $0-5$ ) in the
\end{abstract}

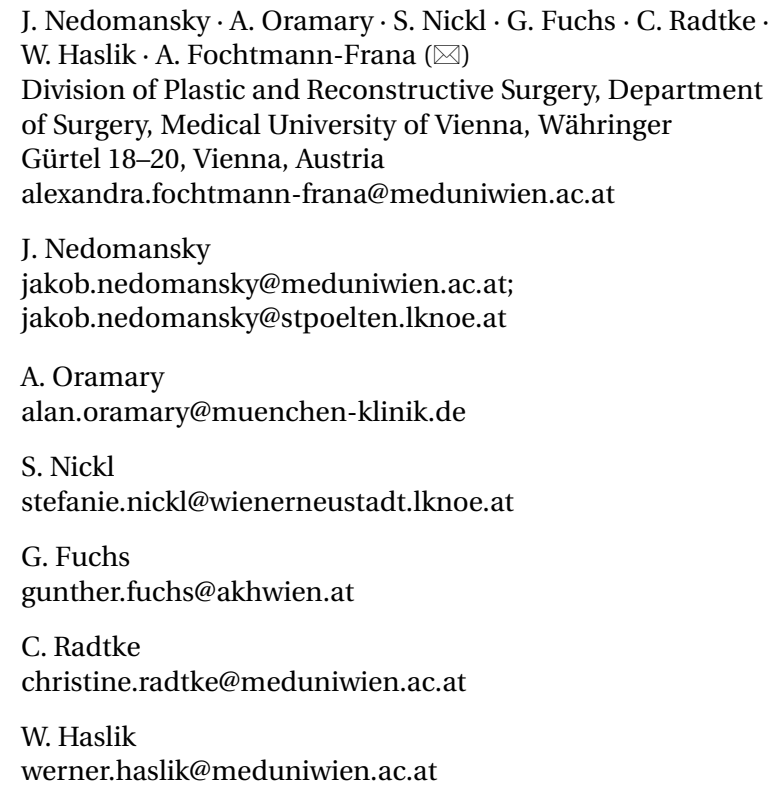

superficial partial thickness and 3 (range 1-11) in the deep partial thickness group. Conservative treatment of deep partial thickness wounds was possible in $79 \%$ and $17 \%$ of these patients required secondary scar revision. Although bacterial colonization of the wounds frequently occurred, wound infections were rarely observed.

Conclusion Acticoat $7^{\mathrm{TM}}$ is a valuable dressing for treating superficial and deep partial thickness burn wounds of the face in an intensive care unit setting. It enables extended time intervals between dressing changes without an increased risk for complications.

Keywords Burn injury · Facial burns · Silver dressing $\cdot$ Thermal injury $\cdot$ Intensive care unit

\section{J. Nedomansky \\ Division of Plastic and Reconstructive Surgery, University Hospital of St. Pölten, St. Pölten, Austria}
A. Oramary
Department of Plastic, Reconstructive, Hand, and Burn Surgery, StKM-Klinikum Bogenhausen, Academic Teaching Hospital Technical University Munich, Munich, Germany

\section{S. Nickl}
Department for Plastic, Aesthetic and Reconstructive Surgery, State Hospital Wiener Neustadt, Wiener Neustadt, Austria 


\section{Introduction}

Facial burns occur in more than $50 \%$ of patients with extensive burn trauma. The face represents a fundamental part of the personal identity and is of great importance for social interaction. Therefore, treatment of facial burns represents a versatile challenge [1].

Due to the high potential for spontaneous healing of facial burns, early surgical excision of the burn eschar followed by skin grafting is often not indicated as the first-line treatment option [2]. Effective conservative treatment of partial thickness burn wounds of the face is important to avoid delayed wound healing and decrease the risk for hypertrophic scar formation [3]. Hypertrophic scarring in the face often leads to functional limitations (e.g. incomplete closing of the eyelids and eating problems) and social stigmatization [4]. The three-dimensional contour of the face and its steady movements impose high demands on burn dressings used in this area [5]. In the past topical ointments (e.g. Flamazine ${ }^{\mathrm{TM}}$ [Alliance Pharmaceuticals $\mathrm{GmbH}$, Düsseldorf, Germany]) were used at many burn centers but they were associated with extended healing times [6]. Nowadays, there is a wide range of alternatives available for partial thickness burns (e.g. antimicrobial silver dressings, hydrocolloid dressings, bioengineered skin substitutes, polyurethane film dressings, hydrogel dressings and silicon-coated nylon dressings) and compared to topical ointments, most of them require fewer dressing changes before complete re-epithelialization takes place [7].

Acticoat7 ${ }^{\mathrm{TM}}$ (Smith \& Nephew GmbH, Hamburg, Germany) is a nanocrystalline silver dressing, which consists of a rayon/polyester core and a silver-coated high-density polyethylene mesh. Acticoat $7^{\mathrm{TM}}$ provides constant release of silver for up to 7 days and therefore can be left on the wounds for up to 7 days $[8,9]$. The main goal of this study was to retrospectively evaluate outcomes after conservative treatment of superficial and also deep partial thickness burns of the face with Acticoat7 ${ }^{\mathrm{TM}}$.

\section{Patients, material and methods}

\section{Study design and population}

This retrospective study analyzed data from all patients with superficial and deep partial thickness facial burns treated at the 6-bed intensive care unit (ICU) of the Vienna General Hospital between 2008 and 2017. All patients included were treated with Acticoat $7^{\mathrm{TM}}$, a wound dressing containing nanocrystalline silver. The data were obtained from scanned patient charts. Approval from the local ethics committee (No. 1183/2017) was obtained. Patients transferred to the burn unit after initial treatment at external hospitals, patients who died during the course of treatment and patients suffering from third degree facial burns were excluded. The primary endpoint was determined as

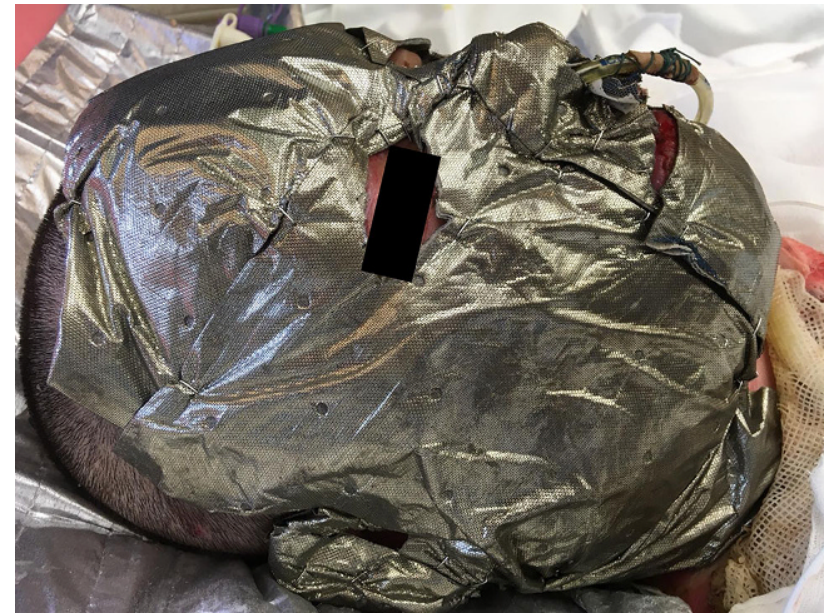

Fig. 1 Applied Acticoat $7^{\mathrm{TM}}$ mask fixed with skin staples

surgery required or not. A secondary endpoint was determined as need for secondary scar revision.

\section{Initial wound management}

All patients admitted to the ICU for burn trauma were evaluated for the extent and depth of the burn wounds. In cases of involvement of the face hair of the scalp and beard were shaved. Blisters were removed and the wounds were treated with an antiseptic agent (Lavasorb ${ }^{\circledR}$, Fresenius Kabi AG, Bad Homburg, Germany) and digital photographic documentation was performed. A senior physician determined the burn depth by bedside examination on the day of admission. Finally, Acticoat $7^{\mathrm{TM}}$ was applied and fixed with small skin staples (see Fig. 1).

\section{Further wound management}

Acticoat $7^{\mathrm{TM}}$ was moisturized in the course of the treatment with sterile distilled water twice a day. Dressing changes were performed after 7 days. When a dressing change took place a mechanical cleaning of the wounds was performed. Necrotic tissue was removed by means of moist compresses and the wounds were cleaned, shaved, and evaluated for the necessity of further Acticoat $7^{\mathrm{TM}}$ treatment.

in the case of re-epithelialization, Acticoat7 treatment was terminated and moisturizing ointments were recommended. In our institution all burn patients had follow-up appointments on a regular basis (6 weeks, 3 months, 6 months, 1 year and 2 years after discharge and after that every year). Close outpatient follow-up visits were required to regularly check on the process of wound healing, compression clothes, and scar formation. When required secondary scar revision was conducted. 


\section{Obtained data}

We analyzed demographic data (age, sex and trauma mechanism), burn depth, affected total body surface area (TBSA), days until healing, bacterial colonization, wound infections, concomitant trauma and need for secondary surgical scar correction.

\section{Statistical analysis}

Demographic data, such as sex, trauma mechanism, bacterial colonization, depth of the burn wound and complications are presented in total numbers and percentages. Metric values, such as age, days until completed healing, number of dressing changes, percentage of burned body surface area, are presented as mean \pm standard deviation and median values (minimum-maximum). The normality of distribution was determined using the Shapiro-Wilk test. All statistical analysis was performed with SPSS 15.0.1 for Windows (IBM, Armonk, NY, USA).

\section{Results}

\section{Patient characteristics}

A total of 100 patients who underwent treatment of superficial and deep partial thickness burns of the face with Acticoat $7^{\mathrm{TM}}$ were included of which 64 were women and 36 men with an average age of $46 \pm 18$ years (Table 1 ).

\section{Burn depth, extent and additional trauma}

Of the patients $62(62 \%)$ had superficial and $38(38 \%)$ had deep partial thickness burns. Median affected TBSA was $25 \%$ (range $2-80 \%$ ). Additional trauma to

Table 1 Patient characteristics

\begin{tabular}{|l|l|}
\hline $\begin{array}{l}\text { Characteristic } \\
\text { Age (years) }\end{array}$ & $N=100$ \\
\hline $\begin{array}{l}\text { Mean } \pm \text { SD } \\
\text { Sex }\end{array}$ & $46 \pm 18$ \\
\hline Male & 36 \\
\hline Female & 64 \\
\hline TBSA (\%) & \\
\hline Median (minimum-maximum) & $25(2-80)$ \\
\hline Burn depth & \\
\hline Superficial partial thickness & $62 \%$ \\
\hline Deep partial thickness & $38 \%$ \\
\hline Trauma mechanism & \\
\hline Combustion & $84 \%$ \\
\hline Scalding & $11 \%$ \\
\hline Electrical burn & $4 \%$ \\
\hline Chemical burn & $1 \%$ \\
\hline TBSA total body surface area, SD standard deviation & \\
\hline
\end{tabular}

Table 2 Outcomes of conservative treatment in different burn depths

\begin{tabular}{|c|c|c|}
\hline Outcome & $\begin{array}{l}\text { Superficial partial } \\
\text { thickness } \\
n=62\end{array}$ & $\begin{array}{l}\text { Deep partial thick- } \\
\text { ness } \\
n=38\end{array}$ \\
\hline \multicolumn{3}{|l|}{ Healing time (days) } \\
\hline Median (min-max) & $14(6-42)$ & $24(9-88)$ \\
\hline \multicolumn{3}{|l|}{ Dressing changes } \\
\hline Median (min-max) & $1(0-5)$ & $3(1-11)$ \\
\hline Missing data & 8 patients & 5 patients \\
\hline
\end{tabular}

the eyes and the respiratory system occurred in $56 \%$ and $27 \%$, respectively.

\section{Healing time superficial partial thickness (Ila) wounds} $(n=62)$

Median healing time was 13 days (range 6-32 days) with a median dressing change rate of 1 (range $0-5$ ). None of the superficial partial thickness wounds required primary or secondary surgery. The number of dressing changes and healing times were not documented in 8 patients (13\%, Table 2$)$.

\section{Healing time deep partial thickness (IIb) wounds $(n=38)$}

Of the patients with deep partial thickness wounds $30 / 38(79 \%)$ were treated solely conservatively with a median healing time of 24 days (range 9-88 days) and a median of 3 (range 1-11) dressing changes (Table 2). Of the patients $8 / 38(21 \%)$ were initially treated with Acticoat $7^{\mathrm{TM}}$ and required surgery during the further course of treatment. The surgical treatment (debridement and skin or keratinocyte grafting) was necessary due to wound infections or prolonged healing time. Median total healing time for these patients was 34 days (range 15-61 days, conservative treatment and postoperative period).

\section{Secondary scar revision}

Of the 30 patients with deep partial thickness burns, who were treated conservatively $5(17 \%)$ required secondary scar revision. Functional areas impaired by hypertrophic scarring were the eyelids and the mouth ( $n=1$ eyelid, $n=1$ eyelid and mouth and $n=3$ mouth). None of the patients with superficial partial thickness burns developed hypertrophic scarring leading to functional impairment.

\section{Bacterial colonization}

Wound swabs were taken in $48 \%$ of the patients and $79 \%$ of these swabs were positive. The majority (63\%) of microbiological analysis of wound swabs taken from the facial area showed colonization with more than one microbial agent (Fig. 2). Multidrug-resis- 
Fig. 2 Types of microorganisms detected in wound swabs taken from the facial area

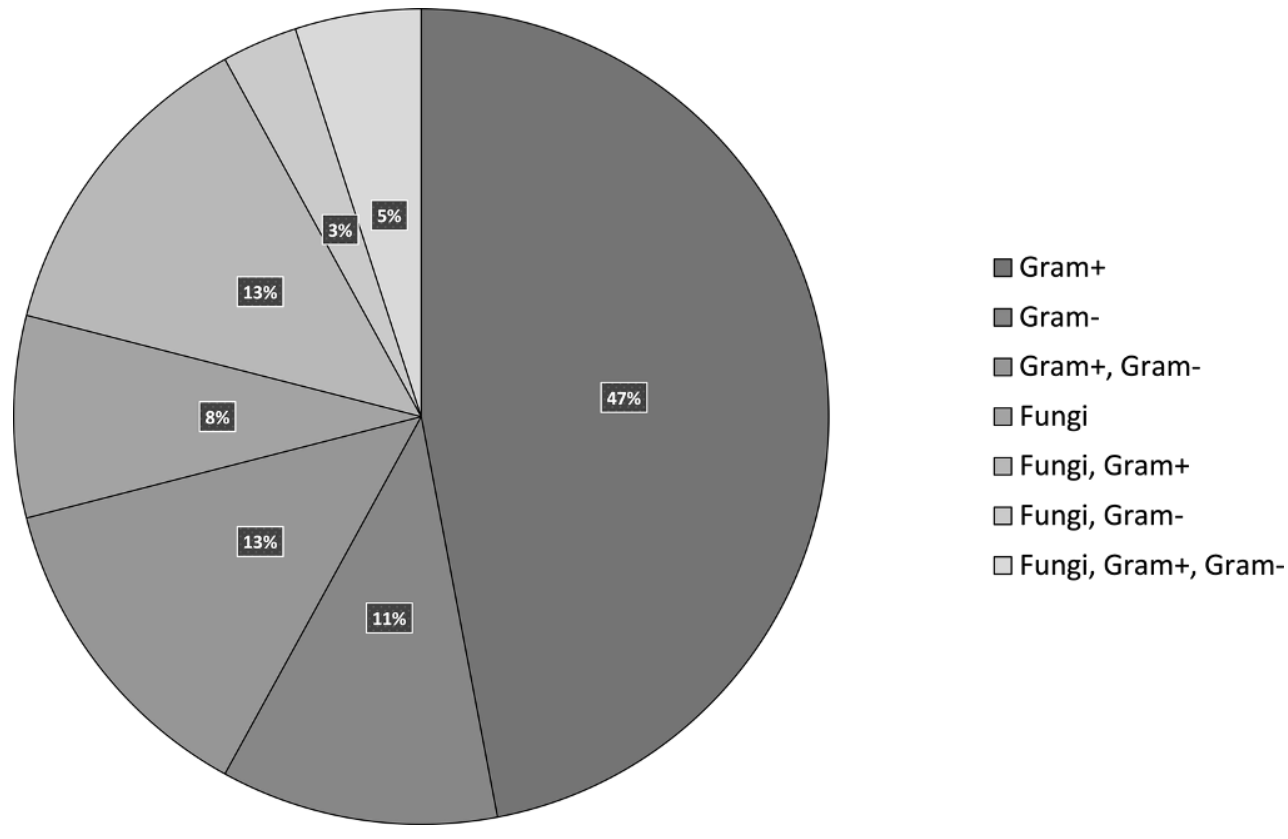

tant (MDR) bacteria were detected in wound swabs of two patients. One patient showed growth of methicillin-resistant Staphylococcus aureus (MRSA) and another patient showed growth of carbapenem-resistant Pseudomonas aeruginosa 3MRGN (multidrugresistant gram-negative pathogens with resistance to three antibiotic groups [defined by the German Commission for Hospital Hygiene and Infection Prevention]). The types of microorganisms detected in wound swabs taken from the facial area are shown in the pie chart in Fig. 2.

\section{Case reports}

\section{Case report 1}

A 41-year-old male patient was admitted to the burn unit with deep partial thickness and full thickness burns covering 25\% of the TBSA including the face (Fig. 3a). The patient, who had a history of chronic nicotine and intravenous drug abuse, suffered these injuries during a fire in his apartment. After initial wound cleaning, Acticoat $7^{\mathrm{TM}}$ treatment was started. Dressing changes were performed every 7 days and swabs were taken during each dressing change (Fig. 3b, c). The microbiological analysis of the wound swabs showed growth of MRSA, Streptococcus parasanguinis, Klebsiella pneumoniae, Enterococcus faecalis, Candida albicans and Escherichia coli. Treatment required a total of 7 dressing changes with at total healing time of 54 days. The prolonged healing time lead to hypertrophic scarring in the left periorbital region resulting in incomplete eyelid closure. A full-thickness skin graft from the clavicular region was used to release the scar contracture (Fig. 3e).

\section{Case report 2}

A 38-year-old male patient was admitted to the burn unit with superficial and deep partial thickness burns covering $20 \%$ of the TBSA (Fig. 4a). He suffered the injuries doing construction work on a windmill when a fire broke out. Both upper extremities and the face were affected and Acticoat $7^{\mathrm{TM}}$ treatment was started after initial wound cleaning. The facial wounds healed within 14 days requiring only 1 dressing change (Fig. 4b, c and d).

\section{Discussion}

Nanocrystalline silver-impregnated dressings such as Acticoat $7^{\mathrm{TM}}$, provide a steady release of long lasting antimicrobial silver ions to the wound bed while overcoming certain significant drawbacks of formerly used silver dressings $[10,11]$. The possibility to create a full face mask which can be left on the wound bed for up to 7 days (Fig. 1) made Acticoat7 ${ }^{\mathrm{TM}}$ the preferred dressing for facial burns at our burn ICU, given that patients required sedation and mechanical ventilation on admittance.

Whereas the clinical efficacy of Acticoat $7^{\mathrm{TM}}$ has been the focus of interest in adults with superficial partial thickness burns [12] as well as in pediatric populations with different burn depths [13-15] and also in several previous case reports [16, 17], our aim was to evaluate its value in the conservative treatment of superficial and especially deep partial thickness wounds of the face.

A limitation of the present study is the monocentric, retrospective study design without a control group; however, in our institution, primary surgery is only conducted on full thickness facial burns. The 
Fig. 3 Patient presented in case report 1. a Facial burn injury on day of admittance, $\mathbf{b}$ result after 7 days of treatment, c result after 35 days of treatment, d result after 49 days of treatment and e result after complete re-epithelization and scar revision with a full thickness skin graft due to incomplete eye closure of the left eye
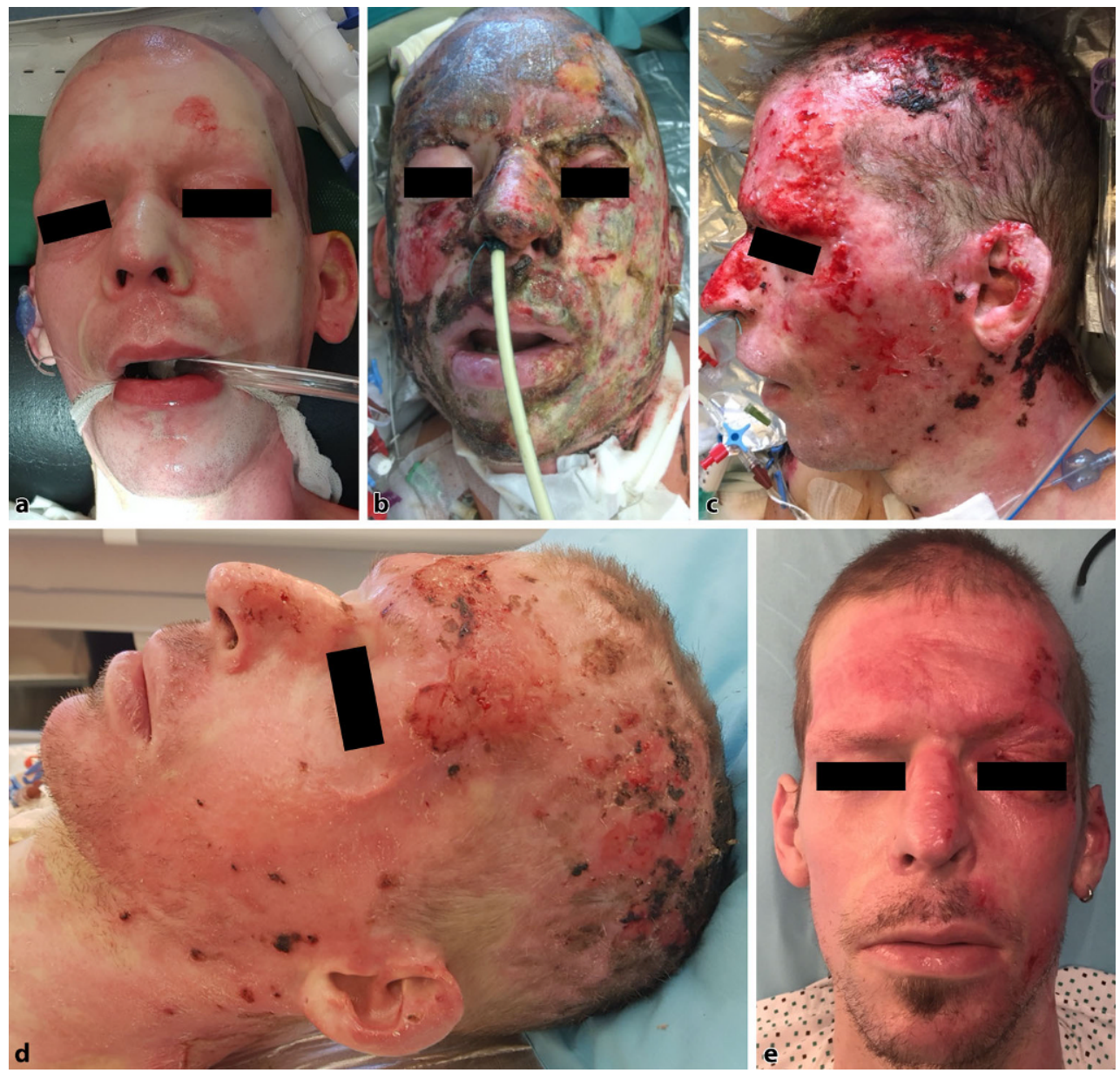

combination of the outstanding tendency for spontaneous healing after facial burn trauma contrasting the relatively frequent esthetically unpleasing results after skin transplantations in the face, led to the conservative treatment plan for deep partial thickness burns of the face at our intensive care unit. The wait and see approach in the acute phase of deep partial thickness burns was effective in the vast majority of patients (79\%) with median healing times of less than 4 weeks only requiring 1 dressing change per week after initial application. In several patients delayed primary surgery had to be performed. Indications for delayed primary surgery were wound infections and absence of complete re-epithelialization. Reducing frequencies of primary surgeries of the face decreased patient morbidity and treatment costs in the acute phase. In most patients with deep partial thickness wounds who were treated conservatively, spontaneous healing did not lead to functionally impairing hypertrophic scarring. Only $17 \%$ of these patients required secondary scar corrections due to disturbing scarring in the eyes, mouth and chin area. In summary, conservative treatment of deep partial thickness burns of the face without secondary scar revision was possible in two thirds of the cases, whereas one third of patients with deep partial thickness burns of the face required either delayed primary or secondary surgical intervention; however, due to the study design it is impossible to know if the good outcome and the relative low number of surgical interventions was only achieved by the Acticoat $7^{\mathrm{TM}}$ treatment. In the present data there is no evidence that only Acticoat $7^{\mathrm{TM}}$ has that effect and other dressing materials have not got a similar effect; however, we strongly believe that the treatment of deep partial thickness facial burns should be conservative. Even the most skilled burn surgeon cannot guarantee to preserve every vital dermal cell. Acticoat $7^{\mathrm{TM}}$ has a favorable texture and can be modelled as a full face mask. In addition to that it is cost-efficient and does not require a secondary dressing. Furthermore, there is no need for daily dressing changes; however, Acticoat $7^{\mathrm{TM}}$ still allows wound inspections, swabs, and debridement with a maximum time frame of 7 days, whereas other dressing material such as Suprathel ${ }^{\circledR}$ (Polymedics Innovations $\mathrm{GmbH}$, Denkendorf, Germany) always requires previous surgical necrosectomy and is left on the wound bed until it peels off by itself. We believe that Acticoat $7^{\mathrm{TM}}$ is the most suitable silver dressing for the conservative treatment of facial burns. Especially in deep partial thickness burn wounds a dressing with high potency 


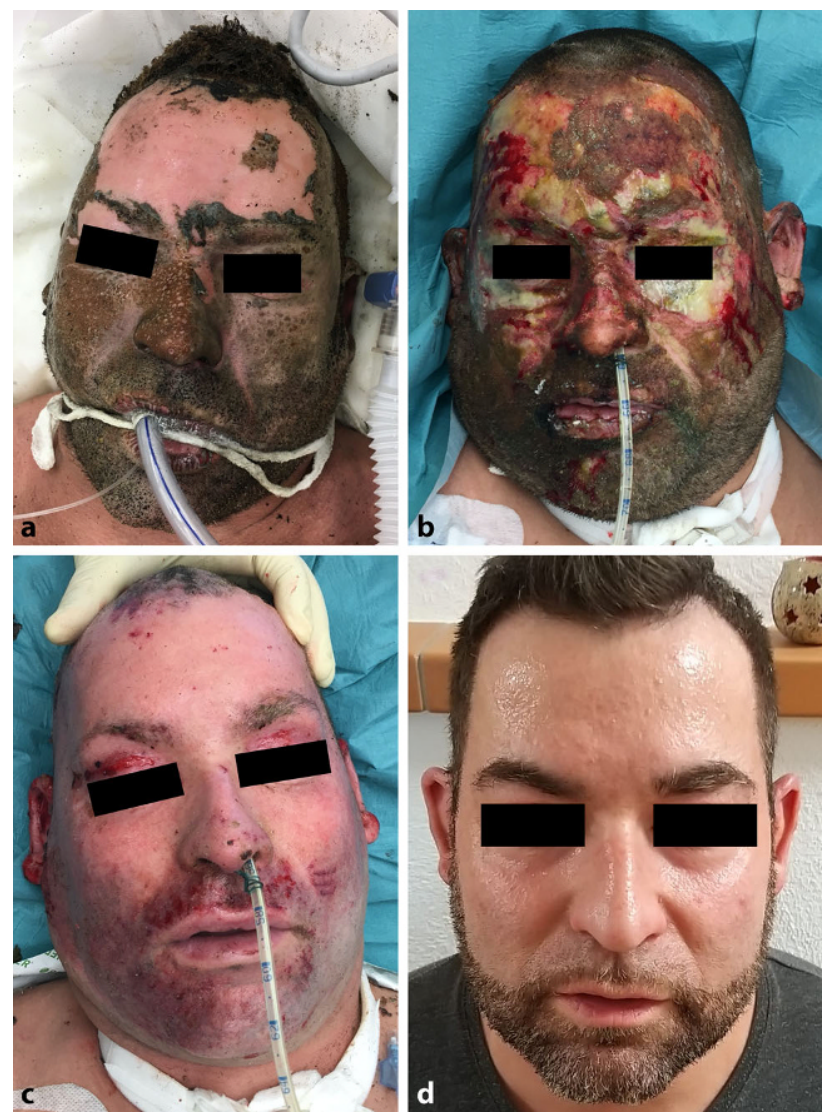

Fig. 4 Patient presented in case report 2. a Facial burn injury on day of admittance, $\mathbf{b}$ result after 7 days of treatment, c result after 14 days of treatment and $\mathbf{d}$ result 18 months after the trauma

against microbial agents is necessary and Suprathel ${ }^{\circledR}$ does not provide this antimicrobial potency [18].

Healing times in the superficial partial thickness group were comparable to the results of Verbelen et al. in their study comparing Acticoat $7^{\mathrm{TM}}$ with Aquacel ${ }^{\circledR} \mathrm{Ag}$ (ConvaTec $\mathrm{GmbH}$, München, Germany), with a mean healing time of 16 days for superficial partial thickness wounds in the Acticoat7 ${ }^{\mathrm{TM}}$ group [12]. In our patient collective superficial partial thickness wounds healed without short-term or long-term complications, such as hypertrophic scarring.

Wound infections rarely occurred (none in the superficial partial thickness group and five in the deep partial thickness group) although analysis of wound swabs showed a high percentage of bacterial colonization $(68 \%$ superficial partial thickness, $88 \%$ in deep partial thickness). The difference in infection rates between the two groups could be due to a better antibacterial efficacy of the silver ions in the well-perfused superficial partial thickness wound bed. Microbial overgrowth leading to infections only occurred in the deep partial thickness group. These wounds might be more susceptible to infection due to restricted blood perfusion and subsequent immunosuppression. In the case of clinically proven wound infection in com- bination with a positive wound swab result, antibiotic treatment was initiated or adapted. To ensure early detection of wound infections in burn patients with deep partial thickness facial burns, dressing changes should probably be performed more frequently than every 7 days; however, a more frequent dressing change could potentially compromise the sensible process of re-epithelialization and might therefore slow down the healing process. Therefore, based on the present study findings a general recommendation regarding time interval between the dressing changes cannot be made.

The thought of using skin staples to secure a dressing in the face might be disturbing at first because of the fear of additional scarring. At follow-up examinations of our patient's visible sequela due to the skin staples were never seen. The face shows a distinctive tendency for swelling within the first hours and days after the burn trauma. Therefore, the first Acticoat7 ${ }^{\mathrm{TM}}$ mask ought to be applied more loosely and sometimes removal of skin staples is necessary in the occurrence of swelling.

In the following treatment course Acticoat $7^{\mathrm{TM}}$ masks should be moisturized twice daily and changed every 7 days. These long intervals between dressing changes avoid unnecessary disruption of the healing process.

Burn depths were always determined clinically by an experienced burn surgeon. Exact healing times could not be determined since the dressing changes were only performed every 7 days. Therefore, the presented numbers are supposedly higher than the actual healing times; however, we believe that the number of necessary dressing changes is a valuable surrogate parameter to evaluate the efficacy of the dressing.

\section{Conclusion}

The fact that the last primary surgery of a deep partial thickness wound of the face at our ICU was performed in 2012, supports our hypothesis that Acticoat7 ${ }^{\mathrm{TM}}$ allows effective conservative treatment of these kinds of wounds with low primary complication rates and a low percentage of secondary scar revisions.

Acknowledgements Our sincere thanks go to the patients who participated in the study.

Funding This research received no specific grant from any funding agency in the public, commercial, or not-for-profit sectors.

Author Contribution J. Nedomansky analyzed and interpreted the patient data and was a major contributor in writing the manuscript. All authors made substantial contributions to the literature search, study design, data collection, analysis and interpretation, drafting the article and revising it critically for important intellectual content and all authors approved the final version to be submitted.

Funding Open access funding provided by Medical University of Vienna. 


\section{Compliance with ethical guidelines}

Conflict of interest J. Nedomansky, A. Oramary, S. Nickl, G. Fuchs, C. Radtke, W. Haslik, and A. Fochtmann-Frana declare that they have no competing interests.

Ethical standards All procedures followed were in accordance with the ethical standards of the responsible committee on human experimentation (institutional and national) and with the Helsinki Declaration of 1975, as revised in 2000. Informed consent was obtained from all patients for being included in the study. Additional written informed consent was obtained from all individual participants or their legal representatives for whom identifying information is included in this article.

Open Access This article is licensed under a Creative Commons Attribution 4.0 International License, which permits use, sharing, adaptation, distribution and reproduction in any medium or format, as long as you give appropriate credit to the original author(s) and the source, provide a link to the Creative Commons licence, and indicate if changes were made. The images or other third party material in this article are included in the article's Creative Commons licence, unless indicated otherwise in a credit line to the material. If material is not included in the article's Creative Commons licence and your intended use is not permitted by statutory regulation or exceeds the permitted use, you will need to obtain permission directly from the copyright holder. To view a copy of this licence, visit http://creativecommons.org/licenses/by/4.0/.

\section{References}

1. Baker RA, Jones S, Sanders C, Sadinski C, Martin-Duffy K, Berchin H, et al. Degree of burn, location of burn, and length of hospital stay as predictors of psychosocial status and physical functioning. J Burn Care Rehabil. 1996;17(4):327-33.

2. Gonzalez-Ulloa M. Quantitative principles in cosmetic surgery of the face (profileplasty). Plast Reconstr Surg Transplant Bull. 1962;29:186-98.

3. Deitch EA, Wheelahan TM, Rose MP, Clothier J, Cotter J. Hypertrophic burn scars: analysis of variables. J Trauma. 1983;23(10):895-8.

4. Achauer BM. Reconstructing the burned face. Clin Plast Surg. 1992;19(3):623-36.

5. Quinn KJ, Courtney JM, Evans JH, Gaylor JD, Reid WH. Principles of burn dressings. Biomaterials. 1985;6(6):369-77.
6. Wasiak J, Cleland H. Burns (minor thermal). BMJ Clin Evid. 2009;2009:1903.

7. Wasiak J, Cleland H, Campbell F. Dressings for superficial and partial thickness burns. Cochrane Database Syst Rev. 2008;4:CD2106.

8. Wright JB, Lam K, Hansen D, Burrell RE. Efficacy of topical silver against fungal burn wound pathogens. Am J Infect Control. 1999;27(4):344-50.

9. Wright JB, Lam K, Burrell RE. Wound management in an era of increasing bacterial antibiotic resistance: a role for topical silver treatment. Am J Infect Control. 1998;26(6):572-7.

10. Dunn K, Edwards-Jones V. The role of Acticoat with nanocrystalline silver in the management of burns. Burns. 2004;30(1):S1-9.

11. Khundkar R, Malic C, Burge T. Use of Acticoat dressings in burns: what is the evidence? Burns. 2010;36(6):751-8.

12. Verbelen J, Hoeksema H, Heyneman A, Pirayesh A, Monstrey S. Aquacel $\left({ }^{\circledR}\right)$ Ag dressing versus Acticoat dressing in partial thickness burns: a prospective, randomized, controlled study in 100 patients. Part 1: burn wound healing. Burns. 2014;40(3):416-27.

13. Brown M, Dalziel SR, Herd E, Johnson K, Wong She R, Shepherd M.A randomized controlled study of silver-based burns dressing in a pediatric emergency department. JBurn Care Res. 2016;37(4):e340-7.

14. Cuttle L, Naidu S, Mill J, Hoskins W, Das K, Kimble RM. A retrospective cohort study of Acticoat versus Silvazine in a paediatric population. Burns. 2007;33(6):701-7.

15. Rustogi R, Mill J, Fraser JF, Kimble RM. The use of Acticoat in neonatal burns. Burns. 2005;31(7):878-82.

16. Burd A, Zeng A. Changing persprectives in paediatric burns care. Hong Kong J Paediatr. 2003;8:272-82.

17. Marazzi M, De Angelis A, Ravizza A, Ordanini MN, Falcone L, Chiaratti A, et al. Successful management of deep facial burns in a patient with extensive third-degree burns: the role of a nanocrystalline silver dressing in facilitating resurfacing. Int Wound J.2007;4(1):8-14.

18. Ryssel H, Germann G, Riedel K, Reichenberger M, Hellmich S, Kloeters O. Suprathel-acetic acid matrix versus acticoat and aquacel as an antiseptic dressing: an in vitro study. Ann Plast Surg. 2010;65(4):391-5.

Publisher's Note Springer Nature remains neutral with regard to jurisdictional claims in published maps and institutional affiliations. 